Ichiro Nakazawa · Toshiaki Nakajima

Tomoaki Ishigami · Satoshi Umemura • Mitsuru Emi

\title{
Linkage disequilibrium and haplotype analysis among eight novel single-nucleotide polymorphisms in the human tissue-type plasminogen activator $(t-P A)$ gene
}

Received: January 22, 2001 / Accepted: March 26, 2001

\begin{abstract}
Tissue-type plasminogen activator (t-PA), a serine protease, activates the conversion of plasminogen to the fibrinolytic protein, plasmin. The $t-P A$ gene, mapped to chromosome 8p12-p11.2, contains 14 exons. An Alu insertion/deletion (I/D) polymorphism in this gene has been associated with an increased risk for myocardial infarction. In the work reported here we sequenced 11 kilobases $(\mathrm{kb})$ of genomic DNA from 50 normal Japanese volunteers (100 alleles), to include all 14 exons of the $t-P A$ gene, flanking intronic sequences, and $6 \mathrm{~kb}$ of the $5^{\prime}$ sequence. These experiments identified eight novel single-nucleotide polymorphisms (SNPs), in addition to the known Alu I/D polymorphism, from which genotypic data we constructed 12 haplotypes in the tested population. Two-way comparisons of SNPs and the Alu polymorphism revealed strong linkage disequilibrium between the Alu site and SNPs at positions $20,209\left(\chi^{2}=92.263\right)$ and $27,555\left(\chi^{2}=47.53\right)$, and between SNPs at positions 27,849 and 28,902 $\left(\chi^{2}=66.331\right)$. A phylogenic tree was constructed to infer a process of genome construction that would reflect the sequence variations we observed. Our results help to explain the lack of agreement among results of various disease-association studies in which a contribution of the human $t-P A$ gene has been suspected but not always confirmed.
\end{abstract}

Key words Tissue type plasminogen activator (t-PA) . Linkage disequilibrium $\cdot$ Single-nucleotide polymorphisms (SNPs) · Alu I/D polymorphism · Phylogenic tree

I. Nakazawa $\cdot$ T. Nakajima $\cdot$ M. Emi $(\square)$

Department of Molecular Biology, Institute of Gerontology, Nippon Medical School, 1-396 Kosugi-cho, Nakahara-ku, Kawasaki 211-8533, Japan

Tel. +81-44-733-5230; Fax +81-44-733-5192

e-mail: memi@nms.ac.jp

I. Nakazawa $\cdot$ T. Ishigami $\cdot$ S. Umemura

Second Department of Internal Medicine, Yokohama City

University School of Medicine, Yokohama, Japan

T. Nakajima

Laboratory of Genetic Diagnosis, Institute of Medical Science,

University of Tokyo, Tokyo, Japan

\section{Introduction}

Elevated levels of tissue-type plasminogen activator (t-PA) antigen may predict risk of future myocardial infarction (MI) and thrombotic stroke (Ridker et al. 1993, 1994; Zunker et al. 1999). It is also thought that $t-P A$ plays an important role in the etiology of inflammation, the healing of injuries, the prognosis and metastasis of cancer, and the susceptibility to other diseases (Duffy et al. 1988; Brommer et al. 1992; Yamashita et al. 1992; Schafer et al. 1994).

Defective activity of $t-P A$, a serine protease that activates the conversion of plasminogen to the fibrinolytic protein, plasmin, plays an important role in the pathogenesis of MI (Fuster et al. 1992). The enzyme is administered therapeutically in patients with MI and in those with other thrombotic diseases, such as pulmonary embolism. When initiated early after the onset of MI, the intravenous infusion of t-PA rapidly dissolves clots in coronary arteries and decreases mortality (Fibrinolytic Therapy Trialists' [FTT] Collaborative Group 1994).

The human $t-P A$ gene has been mapped to chromosome 8p12-p11.2. Its 14 exons span $37 \mathrm{~kb}$ of genomic DNA (Sandra et al. 1986). Ludwig et al. (1992) described an Alurepeat insertion/deletion (I/D) polymorphism in intron 8 of the $t-P A$ gene as the basis for observed restriction fragmentlength polymorphism, and the insertion allele was later implicated in the development of MI (van der Bom et al. 1997). Some subsequent studies supported that result, but others found no association, and the conclusion remains controversial (Ridker et al. 1997).

In the present work, we identified eight single-nucleotide polymorphisms (SNPs) at the $t-P A$ locus by sequencing an $11-\mathrm{kb}$ genomic sequence in DNA from 50 Japanese individuals (100 alleles), and we theanalyzed haplotypes and allelic frequencies. We also looked for linkage disequilibrium among the SNPs and the I/D polymorphism, in the hope of explaining the genetic diversity we found at this locus in our small test population. 


\section{Materials and methods}

\section{DNA samples}

Blood samples were drawn into heparinized tubes, and the leukocyte pellets were separated. Genomic DNA was extracted from the white-cell layer by standard techniques (Emi et al. 1999), and 50ng of each DNA was used for the polymerase chain reaction (PCR). All subjects gave their written informed consent to participate in the study and to supply blood samples for DNA analysis.

\section{Polymerase chain reactions}

Primers for PCR experiments were designed on the basis of the $t-P A$ gene sequence (Genbank accession numbers, K03021 and Z48484), to amplify fragments that, together, would include all 14 exons, flanking intronic sequences and $6 \mathrm{~kb}$ of the 5' flanking region (Bulens et al. 1995; Sandra et al. 1986; Nakajima et al. 2000). Amplifications of genomic DNA took place in volumes of $10 \mu \mathrm{l}$, containing $20 \mathrm{mM}$ Tris$\mathrm{HCl}$ ( $\mathrm{pH}$ 8.0), $2 \mathrm{mM} \mathrm{MgCl}_{2}, 50 \mathrm{mM} \mathrm{KCl}, 2.5 \mathrm{mM}$ each dNTP, and $0.5 \mathrm{U}$ of ExTaq polymerase (Takara Shuzou, Kyoto, Japan). The reactions proceeded in 30 cycles of $30-\mathrm{s}$ denaturation at $94^{\circ} \mathrm{C}, 30$-s annealing at $58^{\circ} \mathrm{C}-62^{\circ} \mathrm{C}$, and 30 -s to 1 -min elongation at $72^{\circ} \mathrm{C}$, as described previously (Tsukamoto et al. 1998; Watanabe et al. 1998). A 2- $\mu$ l aliquot from each reaction was assayed on $1.0 \%$ agarose gel to confirm the product, and the remainder was purified using Multiscreen FB (Millipore, Bedford, MA, USA).

\section{Direct sequencing}

DNA sequencing was done with the BigDye Terminator Cycle Sequencing FS (PE Biosystems, Foster City, CA, USA) and determined with an ABI PRISM 377-96 sequencer (Applied Biosystems, Foster City, CA, USA), as described by Seki et al. (2000). Results were processed with Sequencher, version 3.0 (Hitachi Software, Yokohama, Japan), to compare sequences and to locate polymorphisms (Nakajima et al. 1999). Polymorphisms were confirmed by sequencing with reverse primers.

\section{Genotyping of the Alu I/D polymorphism}

Alleles of the Alu-repeat polymorphism in intron 8 were identified in all 50 subjects by PCR amplification of the appropriate fragments (967/655bp) of the $t P A$ gene, followed by electrophoresis in agarose gel in the manner described by Ludwig et al. (1992).

Determination of haplotype frequencies, tests of linkage disequilibrium, and construction of most-probable phylogenic tree

Haplotype frequencies in the 100 alleles investigated were calculated with Arlequin software (Genetics and Biometry
Laboratory, Geneva, Switzerland). We investigated linkage disequilibrium for all possible two-way comparisons of the novel SNPs and the Alu I/D polymorphism, using several widely employed methods (D, D', and $r^{2}$; Lewontin 1988; Miller et al. 2000). That is, for loci $L_{A}$ and $L_{B}$, each with two alleles $A(B)$ and $a(b)$, let $p_{A}$ be the frequency of allele $A$, let $p_{A B}$ be the frequency of the $A B$ haplotype, and (in general) $p_{i}$ be the frequency of allele $i$, and $p_{i j}$ the frequency of the $i j$ haplotype. The coefficient of disequilibrium, $\mathrm{D}$, is the difference between the observed haplotype frequency and the frequency expected under statistical independence: $\mathrm{D}=p_{A B} p_{a b}-p_{A b} p_{a B}$. The normalized disequilibrium coefficient is obtained by dividing $D$ by its maximum possible value $\left(\mathrm{D}^{\prime}=\mathrm{D} /|\mathrm{D}|_{\max }\right) ;|\mathrm{D}|_{\max }=\min$ $\left(p_{A} p_{B}, p_{a} p_{b}\right)$ if $\mathrm{D}<0$, and $|\mathrm{D}|_{\text {max }}=\min \left(p_{A} p_{b}, p_{a} p_{B}\right)$ if $\mathrm{D}>0$. The correlation coefficient is $r^{2}=\mathrm{D}^{2} /(\mathrm{A} \mathrm{B} \mathrm{a} \mathrm{b})$. Significance levels were determined by $\chi^{2}$ statistics for the corresponding $2 \times 2$ table. The DNAPARS program in PHYLIP 3.6 (Felsenstein 2000) was used to infer the maximum parsimony tree for the seven major haplotypes, and an unrooted phylogenic tree was drawn using DRAWTREE in PHYLIP 3.6.

\section{Results}

By sequencing both $t-P A$ alleles from 50 individuals we found eight novel SNPs, four in the $5^{\prime}$ flanking region, at positions -5280 (C/A), -4358 (G/C), -3403 (G/A), and $-15(\mathrm{~T} / \mathrm{C})$, respectively. Two silent SNPs were found in coding sequences, one at position 20,209 (exon 6) and the other at 28,902 (exon 13). The remaining two SNPs were at positions 27,555 (intron 10) and 27,849 (intron 11). All 50 subjects were typed for the Alu I/D polymorphic site; 15 (30\%) were genotype II, 25 (50\%) were genotype ID, and $10(20 \%)$ were genotype DD. Distributions of genotypes and allele frequencies among all nine polymorphisms are shown in Table 1 . The distribution of Alu I/D alleles in our Japanese subjects was similar to that previously reported in Caucasians. The observed allelic frequencies at each newly identified SNP and the I/D polymorphism were in HardyWeinberg equilibrium.

Construction of haplotypes and calculation of their frequencies were carried out using the Arlequin algorithm; the results are summarized in Table 2. The SNPs at -5280 , -3403 , and -15 were excluded from this analysis because their minor alleles were too rare. Nevertheless, we identified 12 distinct haplotypes among the 50 Japanese subjects, and 3 of them were more frequent than $10 \%$. Three haplotypes contained the insertion allele of the Alu I/D polymorphism; 1 of them (I-1; Table 2) accounted for $49 \%$ of these haplotypes. In contrast, there were 9 haplotypes with the D allele, the highest frequency being $14 \%$ (D-1).

We analyzed linkage disequilibrium for all possible twoway comparisons of SNPs and the Alu I/D polymorphism by several methods (D, $\mathrm{D}^{\prime}, r^{2}$, and the $\chi^{2}$ test). The results are shown in Table 3. Again, SNPs with rare alleles (at positions $-5280,-3403$, and -15 ) were excluded from the analysis. Strong linkage disequilibrium was identified be- 
Table 1. Genotype and allele frequencies of eight SNPs and the Alu I/D polymorphism in the human $t-P A$ gene

\begin{tabular}{|c|c|c|c|c|c|c|}
\hline Gene & $\begin{array}{l}\text { Nucleotide } \\
\text { position }\end{array}$ & $\begin{array}{l}\text { Genotype } \\
(n=50)\end{array}$ & $\begin{array}{l}\text { Allele } \\
\text { frequencies }\end{array}$ & & & \\
\hline \multirow[t]{2}{*}{ 5' Flanking } & $-5,280$ & $\mathrm{C} / \mathrm{C}$ & $\mathrm{C} / \mathrm{A}$ & $\mathrm{A} / \mathrm{A}$ & $\mathrm{C}$ & A \\
\hline & $(\mathrm{C} / \mathrm{A})$ & 49 & 1 & 0 & $99 \%$ & $1 \%$ \\
\hline \multirow{2}{*}{ 5' Flanking } & $-4,358$ & $\mathrm{G} / \mathrm{G}$ & $\mathrm{G} / \mathrm{C}$ & $\mathrm{C} / \mathrm{C}$ & $\mathrm{G}$ & $\mathrm{C}$ \\
\hline & $(\mathrm{G} / \mathrm{C})$ & 4 & 18 & 28 & $26 \%$ & $74 \%$ \\
\hline \multirow[t]{2}{*}{$5^{\prime}$ Flanking } & $-3,403$ & $\mathrm{G} / \mathrm{G}$ & G/A & $\mathrm{A} / \mathrm{A}$ & G & A \\
\hline & $(\mathrm{G} / \mathrm{A})$ & 49 & 1 & 0 & $99 \%$ & $1 \%$ \\
\hline \multirow[t]{2}{*}{$5^{\prime}$ Flanking } & -15 & $\mathrm{~T} / \mathrm{T}$ & $\mathrm{T} / \mathrm{C}$ & $\mathrm{C} / \mathrm{C}$ & $\mathrm{T}$ & $\mathrm{C}$ \\
\hline & $(\mathrm{T} / \mathrm{C})$ & 48 & 2 & 0 & $98 \%$ & $2 \%$ \\
\hline \multirow[t]{2}{*}{ Exon 6} & 20,209 & $\mathrm{~T} / \mathrm{T}$ & $\mathrm{T} / \mathrm{C}$ & $\mathrm{C} / \mathrm{C}$ & $\mathrm{T}$ & $\mathrm{C}$ \\
\hline & $(\mathrm{T} / \mathrm{C})$ & 14 & 25 & 11 & $53 \%$ & $47 \%$ \\
\hline \multirow[t]{2}{*}{ Intron 8} & Alu I/D & $\mathrm{I} / \mathrm{I}$ & $\mathrm{I} / \mathrm{D}$ & $\mathrm{D} / \mathrm{D}$ & I & D \\
\hline & & 15 & 25 & 10 & $55 \%$ & $45 \%$ \\
\hline \multirow[t]{2}{*}{ Intron 10} & 27,555 & $\mathrm{~A} / \mathrm{A}$ & $\mathrm{A} / \mathrm{T}$ & $\mathrm{T} / \mathrm{T}$ & A & $\mathrm{T}$ \\
\hline & $(\mathrm{A} / \mathrm{T})$ & 2 & 24 & 24 & $28 \%$ & $72 \%$ \\
\hline \multirow[t]{2}{*}{ Intron 11} & 27,849 & $\mathrm{G} / \mathrm{G}$ & G/A & $\mathrm{A} / \mathrm{A}$ & G & A \\
\hline & (G/A) & 38 & 11 & 1 & $87 \%$ & $13 \%$ \\
\hline \multirow[t]{2}{*}{ Exon 13} & 28,902 & $\mathrm{~T} / \mathrm{T}$ & $\mathrm{T} / \mathrm{C}$ & $\mathrm{C} / \mathrm{C}$ & $\mathrm{T}$ & $\mathrm{C}$ \\
\hline & $(\mathrm{T} / \mathrm{C})$ & 39 & 11 & 0 & $89 \%$ & $11 \%$ \\
\hline
\end{tabular}

SNP, Single-nucleotide polymorphism; I/D, insertion/deletion

Table 2. Frequencies of haplotypes constructed from five SNPs and the Alu I/D polymorphism

\begin{tabular}{llllllll}
\hline No. & Frequency & $-4,356$ & 20,209 & Intron $8^{\text {a }}$ & 27,555 & 27,849 & 28,902 \\
\hline I-1 & 0.49071 & C & T & I & T & G & T \\
I-2 & 0.03929 & G & T & I & T & G & T \\
I-3 & 0.02000 & C & C & I & T & G & T \\
D-1 & 0.14185 & G & C & D & A & G & T \\
D-2 & 0.13815 & C & C & D & A & G & T \\
D-3 & 0.05454 & G & C & D & T & A & C \\
D-4 & 0.04546 & C & C & D & T & A & C \\
D-5 & 0.02000 & C & C & D & T & G & T \\
D-6 & 0.01568 & C & C & D & T & A & T \\
D-7 & 0.01432 & G & C & D & T & A & T \\
D-8 & 0.01000 & C & C & D & T & G & C \\
D-9 & 0.01000 & G & C & D & T & G & T \\
\hline
\end{tabular}

${ }^{\mathrm{a}} \mathrm{I}$ and $\mathrm{D}$ indicate insertion or deletion alleles of the Alu I/D polymorphism in intron 8 . SNPs at positions

$-5280,-3403$, and -15 were excluded because of low frequencies of the minor alleles

tween the Alu I/D polymorphism and the SNPs at positions $20,209\left(\chi^{2}=92.263\right)$ and $27,555\left(\chi^{2}=47.53\right)$, as well as between the SNPs at positions 27,849 and $28,902\left(\chi^{2}=\right.$ 66.331).

To infer the process of genome construction in the studied population, we constructed a most-probable phylogenic tree on the basis of the haplotypes we determined. The results are presented in Fig. 1. Because of statistical difficulty and controversy regarding details of the method, we used only the seven major haplotypes for constructing the phylogenic tree. We used the parsimony method in the DNAPARS program, and thus constructed one tree with eight changes of base needed on the tree.

We found four differences in nucleotide sequence between the previously published sequence of $t-P A$ and our data (Table 4). However, all of our subjects showed identical nucleotides at the sites in question, and additional sequencing of DNA from 16 Caucasians (32 alleles) yielded results identical to those we obtained in our Japanese panel.

\section{Discussion}

Decreased fibrinolytic activity causes clot formation in coronary arteries and increases the risk of myocardial infarction (MI) (Fuster et al. 1992). In the Rotterdam Study, van der Bom et al. (1997) determined levels of $t-P A$ antigen and $t-P A$ activity in plasma and genotyped the Alu I/D polymorphism in intron 8 of the $t-P A$ gene in 121 patients with MI, and in 250 controls. The insertion allele of the I/D polymorphism was associated with an increased risk of nonfatal MI, and an increased level of $t-P A$ antigen was associated with an increased risk of MI. Several subsequent investigations in other populations yielded different results, usually attributed to ethnic variations (Iacoviello et al. 1996; Ridker et al. 1997).

Until now, polymorphism in the $t-P A$ gene, except for the Alu I/D polymorphism, has not been investigated. We assessed the sequence of all $14 t-P A$ exons, intronic se- 
Table 3. Analysis of linkage disequilibrium for all possible two-way comparisons among five SNPs and the Alu I/D polymorphism ${ }^{\mathrm{a}}$

\begin{tabular}{|c|c|c|c|c|c|c|}
\hline & $\begin{array}{l}-4,358 \\
(\mathrm{G} / \mathrm{C})\end{array}$ & $\begin{array}{l}20,209 \\
(\mathrm{~T} / \mathrm{C})\end{array}$ & Alu I/D & $\begin{array}{l}27,555 \\
(\mathrm{~A} / \mathrm{T})\end{array}$ & $\begin{array}{l}27,849 \\
(\mathrm{G} / \mathrm{A})\end{array}$ & $\begin{array}{l}28,902 \\
(\mathrm{~T} / \mathrm{C})\end{array}$ \\
\hline $\begin{array}{l}-4,358 \\
(\mathrm{G} / \mathrm{C})\end{array}$ & & $\begin{array}{l}\mathrm{D}^{\prime}=0.7149 \\
r^{2}=0.2025 \\
\chi^{2}=20.248 \\
P<10^{-5}\end{array}$ & $\begin{array}{l}\mathrm{D}^{\prime}=0.7252 \\
r^{2}=0.2259 \\
\chi^{2}=22.587 \\
P<10^{-5}\end{array}$ & $\begin{array}{l}\mathrm{D}^{\prime}=0.3689 \\
r^{2}=0.1229 \\
\chi^{2}=12.29 \\
P=0.00045\end{array}$ & $\begin{array}{l}\mathrm{D}^{\prime}=0.3644 \\
r^{2}=0.0565 \\
\chi^{2}=5.649 \\
P=0.01747\end{array}$ & $\begin{array}{l}\mathrm{D}^{\prime}=0.3187 \\
r^{2}=0.0357 \\
\chi^{2}=3.572 \\
P=0.05875\end{array}$ \\
\hline $\begin{array}{l}20,209 \\
(\mathrm{~T} / \mathrm{C})\end{array}$ & & & $\begin{array}{l}\mathrm{D}^{\prime}=1.0 \\
r^{2}=0.9226 \\
\chi^{2}=92.263 \\
P<10^{-5}\end{array}$ & $\begin{array}{l}\mathrm{D}^{\prime}=1.0 \\
r^{2}=0.4385 \\
\chi^{2}=43.853 \\
P<10^{-5}\end{array}$ & $\begin{array}{l}\mathrm{D}^{\prime}=1.0 \\
r^{2}=0.1685 \\
\chi^{2}=16.85 \\
P=0.00004\end{array}$ & $\begin{array}{l}\mathrm{D}^{\prime}=1.0 \\
r^{2}=0.1394 \\
\chi^{2}=13.937 \\
P=0.00019\end{array}$ \\
\hline Alu I/D & & & & $\begin{array}{l}\mathrm{D}^{\prime}=1.0 \\
r^{2}=0.4753 \\
\chi^{2}=47.53 \\
P<10^{-5}\end{array}$ & $\begin{array}{l}\mathrm{D}^{\prime}=1.0 \\
r^{2}=0.1826 \\
\chi=18.263 \\
P<10^{-5}\end{array}$ & $\begin{array}{l}\mathrm{D}^{\prime}=1.0 \\
r^{2}=0.1511 \\
\chi^{2}=15.106 \\
P=0.0001\end{array}$ \\
\hline $\begin{array}{l}27,555 \\
(\mathrm{~A} / \mathrm{T})\end{array}$ & & & & & $\begin{array}{l}\mathrm{D}^{\prime}=-1.0 \\
r^{2}=0.0581 \\
\chi^{2}=5.811 \\
P=0.01593\end{array}$ & $\begin{array}{l}\mathrm{D}^{\prime}=-1.0 \\
r^{2}=0.0481 \\
\chi^{2}=4.806 \\
P=0.02835\end{array}$ \\
\hline $\begin{array}{l}27,849 \\
\text { (G/A) }\end{array}$ & & & & & & $\begin{array}{l}\mathrm{D}^{\prime}=0.8955 \\
r^{2}=0.6633 \\
\chi^{2}=66.331 \\
P<10^{-5}\end{array}$ \\
\hline
\end{tabular}

${ }^{a}$ SNPs at positions $-5280,-3403$, and -15 were excluded because of the rarity of their minor alleles

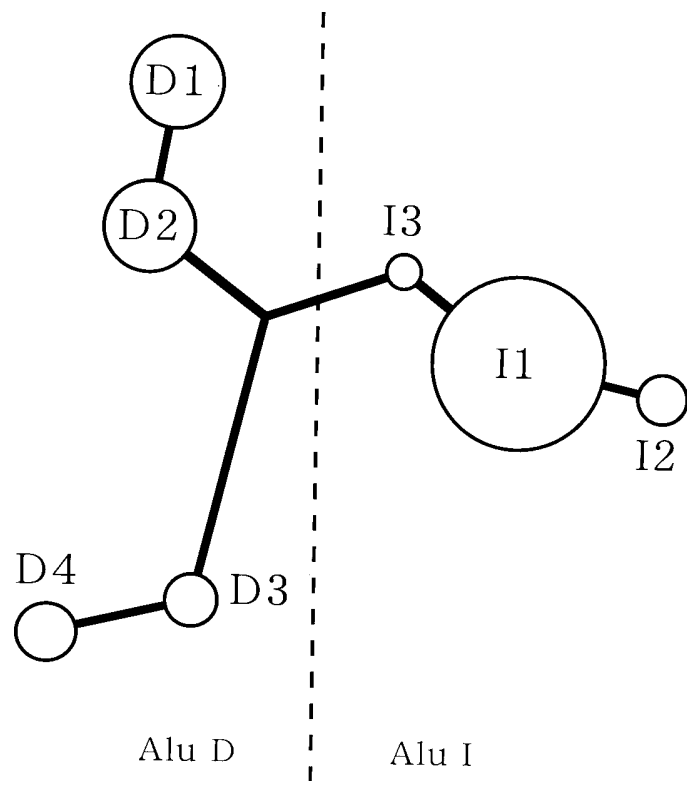

Fig. 1. Phylogenic tree constructed on the basis of the seven major $t$ $P A$ haplotypes in the test population (see Table 2). The area of each circle reflects the relative frequency of that haplotype. The Alu insertion/deletion (I/D) event occurs along the branch at the dotted line. Five of the 12 haplotypes we constructed (D5-D9) were excluded because of their low frequencies

quences flanking each exon, and the upstream region in genomic DNA from 50 Japanese volunteers, and found eight SNPs. Two of them were in exons but did not cause amino-acid replacements. We found four SNPs in the $5^{\prime}$ region; one of them was at position -15 , but its minor allele was rare. Additional investigations will be required to assess the influence of the upstream SNPs on the transcription of $t-P A$.
Table 4. Nucleotides diverging from the sequence of the human $t$ $P A$ gene published by Sandra et al. (1986)

\begin{tabular}{llll}
\hline Position & Published seq. & Japanese $^{\mathrm{a}}$ & Caucasian $^{\mathrm{b}}$ \\
\hline-1007 & $\mathrm{G}$ & $\mathrm{A}$ & $\mathrm{A}$ \\
-539 & $\mathrm{~T}$ & $\mathrm{C}$ & $\mathrm{C}$ \\
-364 & Deletion & $\mathrm{C}$ Insertion & $\mathrm{C}$ Insertion \\
-322 & $\mathrm{C}$ & $\mathrm{T}$ & $\mathrm{T}$ \\
\hline
\end{tabular}

a 100 Alleles

b 32 Alleles

We constructed 12 possible haplotypes from five of the SNPs and the Alu I/D polymorphism. Most of the alleles with insertion of the Alu sequence were the same haplotype (49\%), but haplotypes of alleles with deletion of the Alu sequence were well separated in terms of distribution. Insertion or deletion of the Alu sequence in the human $t-P A$ gene is thought to have occurred early in human evolution, because both alleles occur at similar frequencies in different ethnic groups; the Alu insertion is considered to be the ancestral type, and it is considered that deletion of the sequence occurred afterward (Ludwig et al. 1992). Our data show remarkable haplotype maintenance among alleles that contain the Alu insertion, compared with alleles with the deletion. To speculate on this point, the Alu element may indeed be an insertion rather than a deletion, but the proportion of haplotypes with an I allele (55\%) is too large to support this conclusion.

To infer the process of genome construction from haplotype frequencies is not easy, and the method of doing so is controversial. Although the number of SNPs was small, a phylogenic tree could be constructed from our results, using the parsimony method (Fig. 1). Because it was difficult to place all 12 haplotypes together in one tree, we excluded the 5 haplotypes with low frequencies. With all 12 haplotypes, 
36 equally parsimonious trees were constructed. Uncertainly regarding recombination events is a major limitation for constructing a phylogenic tree, and it is probable that recombinations that have occurred within the $t-P A$ gene over time are responsible for the difficulty we found in constructing a phylogenic tree with all 12 haplotypes.

Five SNPs were in linkage disequilibrium with the Alu I/D polymorphism, two of them being in strong linkage disequilibrium. Moreover, the SNPs at positions 27,849 and 28,902 were in strong linkage disequilibrium with each other. We suggest that recombination within the sequence that includes these two SNPs probably occurred after the Alu I/D event. Linkage disequilibrium in the human genome is still poorly understood, but it is thought to be determined by the age of the markers, the population history, the recombination rate, selection, and genetic drift (Miller et al. 2000). Isolated populations tend to show strong linkage disequilibrium, while population admixture weakens the linkage disequilibrium (Wright et al. 1999).

In the present study, we investigated the Japanese genome; therefore, it is possible that an isolated ethnic trait may have affected our results. However, although we found four nucleotides that diverged from the published $t-P A$ gene sequence, we found identical nucleotides at those sites when we sequenced 32 Caucasian alleles. The eight novel SNPs we identified at that locus are not very likely to change the $t-P A$ phenotype, but they may prove to be useful as genetic markers for population-based disease-association studies. The genetic knowledge of the novel SNPs at the $t$ $P A$ locus, and the relationships among them (including the linkage disequilibrium state), together with the inference regarding the evolutionary relationships of the SNPs described in the present study should facilitate more refined clinical association studies of myocardial infarction by clinical scientists.

\section{References}

Brommer EJ, Dooijewaard G, Dijkmans BA, Breedveld FC (1992) Depression of tissue-type plasminogen activator as an expression of local inflammation. Thromb Haemost 68:180-184

Bulens F, Ibanez-Tallon I, Van Acker P, De Vriese, Nelles L, Collen D (1995) Retinoic acid induction of human tissue-type plasminogen activator gene expression via a direct repeat element located at -7 kilobases. J Biol Chem 270:7167-7175

Duffy MJ, O'Grady P, Devaney D, O'Siorain L, Fennelly JJ, Lijnen HR (1988) Tissue-type plasminogen activator, a new prognostic marker in breast cancer. Cancer Res 48:1348-1349

Emi M, Keicho N, Tokunaga K, Katsumata H, Souma S, Nakata K, Taguchi K, Ohishi N, Azuma A, Kudoh S (1999) Association of diffuse panbronchiolitis with microsatellite polymorphism at the human interleukin 8 (IL-8) locus. J Hum Genet 44:169-172

Felsenstein J (2000) PHYLIP (Phylogeny Inference Package) version 3.6a. Distributed by the author. Department of Genetics, University of Washington, Seattle, USA
Fibrinolytic Therapy Trialists' (FTT) Collaborative Group (1994) Indications for fibrinolytic therapy in suspected acute myocardial infarction: collaborative overview of early mortality and major morbidity results from all randomised trials of more than 1000 patients. Lancet 343:311-322

Fuster V, Badimon L, Badimon JJ, Chesebro JH (1992) The pathogenesis of coronary artery disease and the acute coronary syndromes. $\mathrm{N}$ Engl J Med 326:242-250

Iacoviello L, Di Casstelnuovo A, deKnijff P, D'Orazio A, Amore C, Kluft C, Donati MB (1996) Alu-repeat polymorphism in the tissuetype plasminogen activator $(t-P A)$ gene, $t-P A$ levels and risk of familial myocardial infarction (MI). Fibrinolysis 10 (Suppl 2):1316

Lewontin RC (1988) On measures of gametic disequilibrium. Genetics 120:849-852

Ludwig M, Wohn KD, Schleuning WD, Olek K (1992) Allelic dimorphism in the human tissue-type plasminogen activator (TPA) gene as a result of an Alu insertion deletion polymorphism. Hum Genet 88:388-392

Miller PT, Sardina IB, Saccone NL, Putzel J, Laitinen T, Cao A, Kere J, Pilia G, Rice JP, Kwok PY (2000) Juxtaposed regions of extensive and minimal linkage disequilibrium in human Xq25 and Xq28. Nat Genet 25:324-328

Nakajima T, Hamakubo T, Kodama T, Inazawa J, Emi M (1999) Genomic structure and chromosomal mapping of the human sterol regulatory element binding protein (SREBP) cleavage-activating protein $(S C A P)$ gene. J Hum Genet 44:402-407

Nakajima T, Iwaki K, Kodama T, Inazawa J, Emi M (2000) Genomic structure and chromosomal mapping of the human Siter-1 protease $(S 1 P)$ gene. J Hum Genet 45:212-217

Ridker PM, Baker MT, Hennekens CH, Stampfer MJ, Vaugham DE (1997) Alu-repeat polymorphism in the gene coding for tissue-type plasminogen activator (t-PA) and risk of myocardial infarction among middle-aged men. Arterioscler Thromb Vasc Biol 9:16871690

Ridker PM, Hennekens CH, Vaugham DE (1994) Prospective study of endogenous tissue-type plasminogen activator and risk of stroke. Lancet 343:940-943

Ridker PM, Vaugham DE, Hennekens CH (1993) Endogenous tissuetype plasminogen activator and risk of myocardial infarction. Lancet 341:1165-1168

Sandra J, Friezner D, Rajput B, Reich E (1986) The tissue plasminogen activator gene. J Biol Chem 261:6972-6985

Schafer BM, Maier K, Eickhoff U, Todd RF, Kramer MD (1994) Plasminogen activation in healing human wounds. Am J Pathol 144:1269-1280

Seki T, Tanaka T, Nakamura Y (2000) Genomic structure and multiple single-nucleotide polymorphisms (SNPs) of the thioprine Smethyltransferase (TPMT) gene. J Hum Genet 45:299-302

Tsukamoto K, Haruta K, Shiba T, Emi M (1998) Isolation and mapping of a polymorphic CA repeat sequence at the human interleukin 6 locus. J Hum Genet 43:71-72

van der Bom J, de Knijiff P, Haverkate F, Bots ML, Meijer P, de Jong PTVM, Hofmaan A, Kluft C, Grobbee DE (1997) Tissue plasminogen activator and risk of myocardial infarction. Circulation 95:26232627

Watanabe I, Tsukamoto K, Shiba T, Emi M (1998) Isolation and radiation hybrid mapping of dinucleotide repeat polymorphism at the human matrix Gla protein (MGP) locus. J Hum Genet 43:75-76

Wright AF, Carothers AD, Pirastu M (1999) Population choice in mapping genes for complex diseases. Nat Genet 23:397-404

Yamashita J, Inada K, Yamashita S, Nakashima Y, Matso S, Ogawa M (1992) Tissue-type plasminogen activator is involved in skeletal metastasis from human breast cancer. Int J Clin Lab Res 21:227230

Zunker P, Schick A, Padro T, Kienast J, Phillips A, Ringelstein EB (1999) Tissue plasminogen activator and plasminogen activator inhibitor in patients with acute ischemic stroke. Neurol Res 21:727732 